\title{
TRIP ASSIGNMENT MODELLING FOR AN INDIAN CITY TO ASSESS THE BENEFITS OF PROPOSING RING ROADS
}

\author{
Shilpa Pulinkave Variyam ${ }^{1}$, Anu Plavara Alex ${ }^{2}$, Manju Vasudevan Saraswathy ${ }^{3}$, \\ Shaheem Shahul Hameed ${ }^{4}$ \\ ${ }^{1}$ IPE Global, PMC, Smart City Thiruvananthapuram Limited, India \\ ${ }^{2,3}$ College of Engineering Trivandrum, Kerala, India \\ ${ }^{4}$ National Transportation Planning and Research Centre, Kerala, India
}

Received 26 September 2019; accepted 29 December 2019

\begin{abstract}
Travel demand models are tools used to estimate the travel behaviour of a population. It is used to overcome the previous inefficiencies of the existing transport systems and to produce new transportation facility. This study aimed to develop trip assignment model for Thrissur, an Indian city to assess the benefits of proposing ring roads. Thrissur is struggling to incorporate the increased number of vehicles due to lack of adequate infrastructure and better traffic management programmes. The trip assignment model developed using CUBE 6.4.1 for Thrissur Corporation estimated the link volume counts in the road network and identified the congested roads. The predicted link volumes were compared with the actual volume for validation. This model was used for identifying the improvements required for the road network and two outer ring roads was proposed. The model predicts that the proposed outerring roads can reduce the congestion of Thrissur Corporation.
\end{abstract}

Keywords: trip assignment model, TAZ, congestion, CUBE.

\section{Introduction}

Capturing the human behaviour has an important role in travel decisionmaking process not only for the current transportation conditions but also for the future trends. People travel from one place to another for various activities such as work, education, recreation, etc. Several trips are made by utilizing different alternatives or choices available each day. The efficient use of a transportation system requires proper planning. Travel demand models are tools that estimate the changes in travel behaviour of population. These models give quantitative information on the travel demand and the performance of different alternatives or choices of transportation system. Based on these output, each choice can be compared and proper decisions can be made easily. Several types of travel demand models can be used in a project, such as sketch-planning models, strategicplanning models, trip-based models, and activity-based models. The use of one model over another will depend on the needs of the project as well as availability of data. The classic four step travel demand models are generally used for regional, sub-regional, and project-level analysis and decision-making. In the trip assignment stage, the actual street and highway routes that will be used and the number of automobiles and buses that can be expected on each highway segment are determined. A trip assignment model aims to estimate the volume of traffic on all links

${ }^{2}$ Corresponding author: anualex@cet.ac.in 
of the system, thus simulating the present conditions or for any future year. The impact of this traffic load on the transportation system can also be determined from the model. Parameters, like, distance travelled, travel time, delay, fuel consumption and environmental pollution can be measured from this model. These models can also be used to study the responses of traffic to changes in travel demand, information dissemination, road capacities, signal timings, and road tolls.

A trip assignment model was developed in this study for Thrissur, an Indian city. Thrissur district, the "cultural capital of Kerala State" in India has got a major importance due to the presence of large number of well-known religious buildings, educational institutions, administrative buildings, recreational centres, medical facilities, trade and commercial centres. The city consist of three main bus stations, four railway stations and the city is about $55 \mathrm{kms}$ from Cochin International Airport. The city is filled with several business establishments and commercial industrial units. The growth of service sectors and educational institutions are at a faster rate. The city also houses most of the important religious institutions in Kerala. It thus attracts a number of trips, causing an increase in traffic congestion near the central business district. Thrissur, one of the better planned cities in Kerala, is now struggling to incorporate this increased number of vehicles due to lack of adequate infrastructure and better traffic management programmes. The conflict between intercity and intra city traffic is found to be the main reason for heavy traffic congestion in the city centre. This is due to the absence of properly interconnected road networks and insufficient geometrical conditions of roads. Other reasons are presence of wholesale markets in the city core, inappropriate parking and encroachment of street vendors in the city. Reducing traffic problems in the city is highly essential for solving these issues. The policy of the government is to reduce the traffic growth and to optimise the infrastructure near its optimum. The main objective of this study is to develop a trip assignment model for Thrissur city and to use this model for testing long term congestion mitigation measures. The study has considered National Highway, State Highways, Major District Roads and other main roads near Thrissur central business district. The zonal boundaries are restricted to ward limits. Cube 6.4.1 was used to develop the base year travel demand model, to estimate the future travel demand and to analyses the impact of alternative transportation policy and improvement.

\section{State of the Art}

A well planned and developed transportation system is an essential need for the overall development of a country. Transportation system highly influence the way people organise their lives in terms of residential location, work location, daily activitypatterns, vehicle ownership, choices of mode of transport, route choices etc. (e.g. Cascetta, 2001; de Dios Ortuzar and Willumsen, 2001; Badoe and Miller, 2000; Chakraborty and Mishra, 2013). Various transportation facilities like highways, streets and public transit lanes are designed carefully during the planning stage. Travel demand model is a tool used by the transportation planners to quantify the travel demand in an area and to evaluate the transportation facilities. These models are also capable of calculating the effect of change in population, employment, public transit planning, freight planning and changes in land use in the study area. 
D'Este (1987) considered the flowdependent trip assignment method for a city with less number of radial roads. A system of differential equations was derived for the spatial pattern of trip assignment with a continuous distribution of home locations and a ring-radial road network. This system was solved for a special case of uniform distribution of home locations. Kalic and Teodorovic (2003) examined the application of soft computing techniques in travel demand. The model was tested on a real numerical example. The model successfully solved the trip distribution problem. Teklu et al. (2007) presented a composite frequencybased and schedule-based approach to transit assignment. The proposed model used aggregate line frequencies to parameterise bus headway and a micro-simulator to enforce capacity constraints on individual vehicles. Schmöcker et al. (2008) compared the advantages of schedule-based versus frequency-based transit assignment tools and the applicability of the models. They also proposed a frequency-based dynamic transit assignment model for overcrowded high-frequency transit networks, where passengers might not be able to board vehicle and hence remain on platform. A fail-to-board probability was introduced to reflect passenger's attitude of risk-averse. The expected delay along a hyperpath by a fail-to-board probability is incorporated into a generalised cost function.

Nökel and Wekeck (2009) compared several models of route choice in frequency-based transit assignment in terms of the underlying assumptions on service regularity, passenger information, and choice set structure. Herawati (2011) conducted a study on trip assignment model with consideration of vehicle emission at Cimahi city in Indonesia using CUBE Software. They conducted a study on congestion in the city and reduction in the congestion links by considering the emission cost. The model showed that the combination of road widening and reducing high side friction on arterial roads reduce the congestion both with and without emission cost. Paul A. (2011) showed how traffic assignment models are developed by analyzing the accessibility measures of settlement roads. The study suggested that space syntax is an appropriate method of traffic assignment for cities where OD tripdata is absent. Abdel-Aal (2014) conducted a study on the calibration of trip distribution model for the city of Alexandria. The study developed doubly constrained gravity model for trip distribution. The model represented the trip patterns of the city by different trip purpose. Model validation was done by comparing the trip length distribution, intra-zonal trips and the distribution of the trip interchanges between city parts obtained from the model and the real world data.

Hakimelahi et al. (2014) conducted a study on fuel consumption monitoring. The main objective of the study was to create an accurate correlation between fuel consumption and travel demand modelling. This study evaluated and calibrated travel demand model using Cube software and its relation to fuel consumption, for the city of Shiraz, Iran. Kumar and Peeta (2014) introduced a path-based traffic assignment algorithm for solving the static deterministic user equilibrium traffic assignment problem. It used the concepts of the path shift-propensity factor and the sensitivity of path costs with respect to path flows in the flow update process It was labelled as the slope-based path shift-propensity algorithm (SPSA). It was proved in the study that SPSA is a feasible deployment option under the computational capabilities 
available today. Berki et al. (2017) conducted a study on trip generation and distribution modelling in Budapest. The validity of the resultant model was fairly good and was highly reliable for future studies. Mehta et al. (2017) conducted a study on development of trip distribution model of commercial vehicles in Rajkot city in Gujarat. It was concluded that constructing a new terminal is the solution for reducing the congestion in the city. Toilier et al. (2018) presented one of the mostly operable methods used in urban freight modelling through the FRETURB design. It was proved in the study that the model was able to summarize efficiently the urban freight transport phenomenon and was still statistically robust twenty years after its first design although it needs marginal adaptations on organisational elements.

The reviewed literature illustrates the efficiency of travel demand models to capture the existing scenario and capability to predict the future demand. These models can be effectively used for predicting the impact of short term and long term travel demand management measures and policies. The present case study contributes to the literature by developing trip assignment model for a typical Indian city with multimodal transportation using Cube Software and estimating the contribution of the proposed solution in reducing traffic congestion.

\section{Study Area}

Thrissur, known as the "Cultural capital of Kerala" in India, is developed around 'ThekkinkaduMaidan', a65 acre hillock situated centrally. Map of the study area is shown in Fig. 1. The city is located at $10.52^{\circ} \mathrm{N}$ latitude and $76.21^{\circ} \mathrm{E}$ longitude, with an altitude of $2.83 \mathrm{~m}$ above mean sea level. It is a part of the midland regions of Kerala and an extended part of Palakkad plains. Thrissur Municipal Corporation came into being on $2^{\text {nd }}$ October 2000 with a total area of $101.42 \mathrm{sq} \mathrm{km}$. The total population of Thrissur Corporation in 2011 was 315957 consisting 152296 males and 163661 females. The total households in the city are 78336 and sex ratio is 1.075 . The average population density is 3115 persons per sq. $\mathrm{km}$. The city houses many Central and State government offices, cultural organizations, private sector companies, educational institutions, recreational centres, financial centres and religious institutions. The city is also famous for its prominent gold markets and silk garment trade in India.

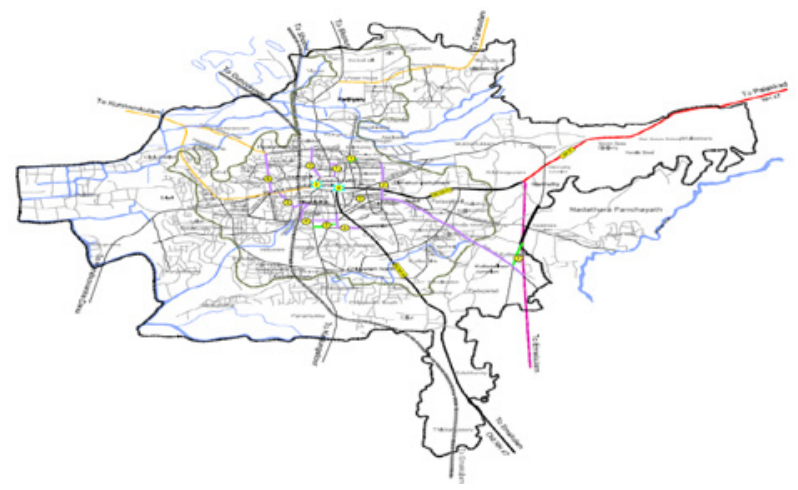

Fig. 1.

Map of Thrissur Corporation Area 
The city consists of road networks in ring and radial pattern originating from Swaraj Round, which is the road surrounding the central hillock. The presence of numerous arterial roads including National and State Highways act as an excellent intercity transportation system. The city is dominated by private buses. The state owned Kerala State Road Transport Corporation (KSRTC) buses, Volvo A/C buses, and auto-rickshaws are the other means of public transportation within the city. Cars and two wheelers are the prominent personalized modes.

\section{Digitization of Road Network and Traffic Analysis Zones}

Digitization of road network and traffic analysis zone map was carried out at this stage. The digitization of roads was done using Google map as base and digitization of zones was done using ward map as base. QGIS and Arc GIS software were used for digitization. National highway, State highways, Major District Roads and other minor roads were coded into the network. The study considered one National Highway, four State Highways, 77 Major District Roads and 16 other roads in the study area.

GIS shape file was converted to network file in CUBE. The attributes provided as input to these links were pavement name, pavement type, number of lanes, divided/ non-divided, one-way/two-way, distance, carriageway width, traffic volume count, free flow speed, journey speed, travel time and capacity.

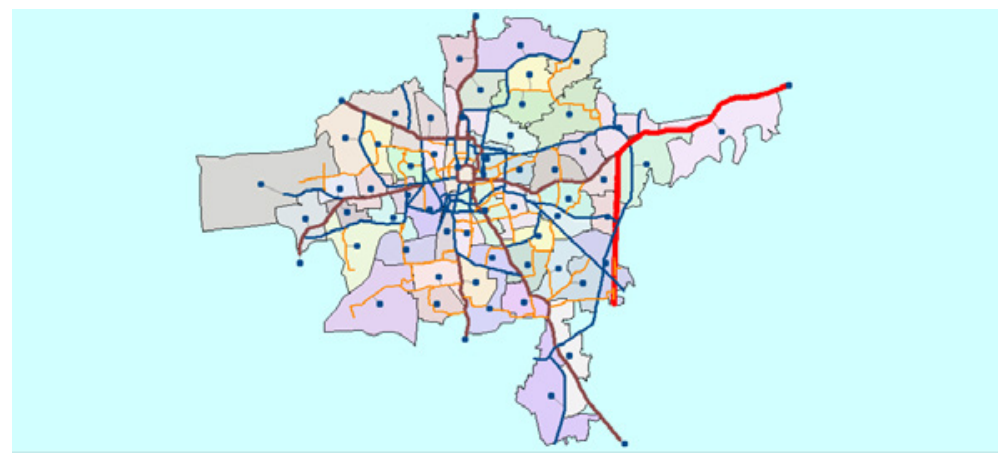

Fig. 2.

Screenshot of TAZ with Road Network

The study area consists of 55 internal zones and 6 internal zones. Geo-referencing was done by considering seven control points along the boundary. Household data and employment data were added into the Traffic Analysis Zones or TAZs. The zonal attributes provided as input to each zone are population, age groups, and employment opportunities, type of employment, total commuters, vehicle ownership and total school enrolment.

\section{Travel Demand Modelling}

Four step travel demand model was developed using CUBE software. The highway network and zonal map were provided as the major input to the model. 
Trip generation, distribution, modal split and trip assignment steps are discussed in detail in the following subsections.

\subsection{Trip Generation}

The first stage was trip generation from which the trip productions and attractions in the study area were obtained. Three trip purposes were considered viz. home-based daily trips (HBD), home-based other trips (HBO) and non-home based trips (NHB). Home based daily trips included both work and education trips. Home based other trips included shopping trips, hospital trips, worship trips and recreational trips. Non home based trips include errands. The trip generation in Cube voyager was done by inputting trip production and attraction equations, database file of TAZs and the external trip numbers. External trip numbers are the trips produced and attracted to the external zones. The trip production and attraction equations were developed as multiple linear regression models in SPSS software and are tabulated in Table 1 . The output of the trip generation step was the trip ends in each zone by trip purposes. These trip ends were balanced and provided as an input to the second step.

\section{Table 1}

Trip Production and Attraction Equations

\begin{tabular}{|c|c|c|}
\hline \multicolumn{2}{|c|}{ Production equations } & \multirow{2}{*}{$\frac{\mathbf{R}^{2}}{0.738}$} \\
\hline 1 & HBD $=-0.28+1.703 \times$ Total commuters $+0.363 \times$ Vehicle ownership & \\
\hline 2 & $\begin{array}{l}\mathrm{HBO}=1.611+0.045 \times \text { Vehicle ownership }+0.119 \times(\text { Age group below } 5 \text { years })+0.188 \times(\text { Age } \\
\text { group between } 5 \text { and } 20)+0.22 \times(\text { Age group between } 20 \text { and } 55)+0.216 \times(\text { Age group above } 55)\end{array}$ & 0.192 \\
\hline 3 & $\begin{array}{l}\mathrm{NHB}=0.209+0.168 \times(\text { Age group between } 5 \text { and } 20)+0.319 \times(\text { Age group between } 20 \text { and } 55)+ \\
0.423 \times(\text { Age group above } 55)\end{array}$ & 0.154 \\
\hline \multicolumn{2}{|r|}{ Attraction equations } & $\mathbf{R}^{2}$ \\
\hline 1 & HBD $=-288.459+6.991 \times($ Total employment number $)+0.513 \times($ Total school enrolment $)$ & 0.975 \\
\hline 2 & $\begin{array}{l}\mathrm{HBO}=377.273+10.277 \times(\text { Employment type } 1)+8.923 \times(\text { Employment type } 3)+43.957 \times \\
(\text { Employment type } 5)\end{array}$ & 0.788 \\
\hline 3 & $\begin{array}{l}\mathrm{NHB}=108.127+2.077 \times(\text { Employment type } 1)+2.114+\text { Employment type } 3)+11.365 \times \\
\text { Employment type } 5)\end{array}$ & 0.802 \\
\hline
\end{tabular}

\subsection{Trip Distribution}

The second step was trip distribution in which the trip productions and attractions for each pair of zones were distributed. The doubly constrained gravity model was used as the trip distribution model for Thrissur city. In the gravity model, the allocation of trips depends on the magnitude of activities at the destination zone and the spatial separation between the zones. The trip ends obtained from trip generation step, highway skim matrix obtained from the network, which is the measure of travel cost between each pair of zones in terms of time and distance and the friction factors were provided as input to the distribution stage. The screenshot of the output from the trip distribution is given in Fig. 3. The output was obtained for all the three trip purposes considered in the study. It shows the number of trips distributed from one zone to another. The trip number was found decreasing as the distance between zones increases. The increased number of trips distributed in certain zones was due to increased activity in that particular zone. The desire line diagram obtained for a zone in the study area is shown in Fig. 4. 


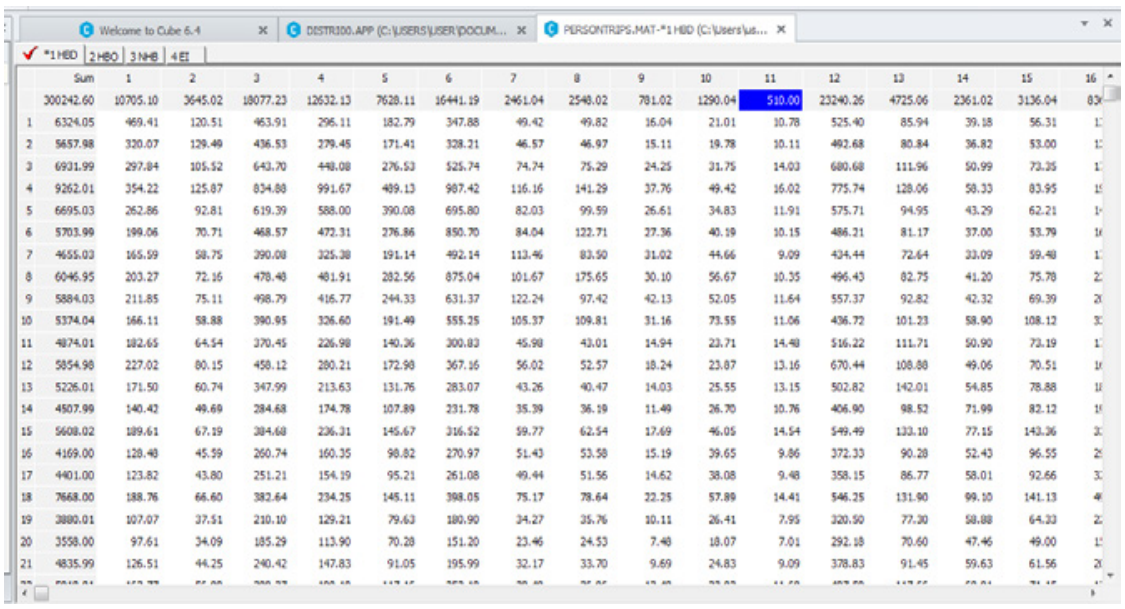

Fig. 3.

OD Matrix Obtained in Person Trips

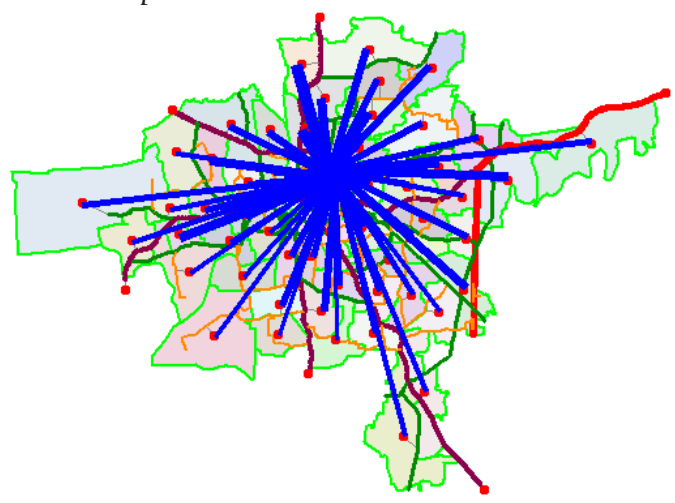

Fig. 4.

Desire Line Diagram

\subsection{Mode Split}

Mode split analysis was done in the next step in which the O-D matrix of person trips from trip distribution stage was split among different zones by modes available. Multinomial Logit models were developed in SPSS for mode split. The modes considered for the study were car, two wheeler, auto rickshaw and bus. The distance travelled was obtained as significant independent variable and bus was considered as reference category. The utility equations obtained for each mode are given (Eq. (1), Eq. (2), Eq. (3)):

$U($ Car $)=-0.549-$ Distance $\times 0.068$

$U($ Two Wheeler $)=4.267-$ Distance $\times 0.780$

$U($ Autorickshaw $)=3.598-$ Distance $\times 0.16$

The resultant matrix obtained from mode split stage was converted to O-D matrix of vehicle trips and were used as input to the trip assignment step. 


\subsection{Trip Assignment}

Trip assignment model estimated the traffic flow on each link in the study area. All or nothing assignment technique was used to assign trips to the network in this study. It was assumed in this technique that the travel time on links does not vary with link flows. The input provided for this step, was highway network and O-D Matrix. The trip assignment output shows the assigned volume counts in each link. The output obtained is shown in the Fig. 5. The variation in thickness shows the variation in volume count in each stretch of the link, i.e. as volume increases thickness also increases. The v/c ratios of the congested roads obtained are shown in Table 2 . These road stretches connects the Central Business District of Trissur with Shoranur, Kuttippuram, Mannuthy, Ernakulam, Vadanappally and Kodungallur. The congestion was mainly due to decreased width of roads and increased number of vehicles and trips.

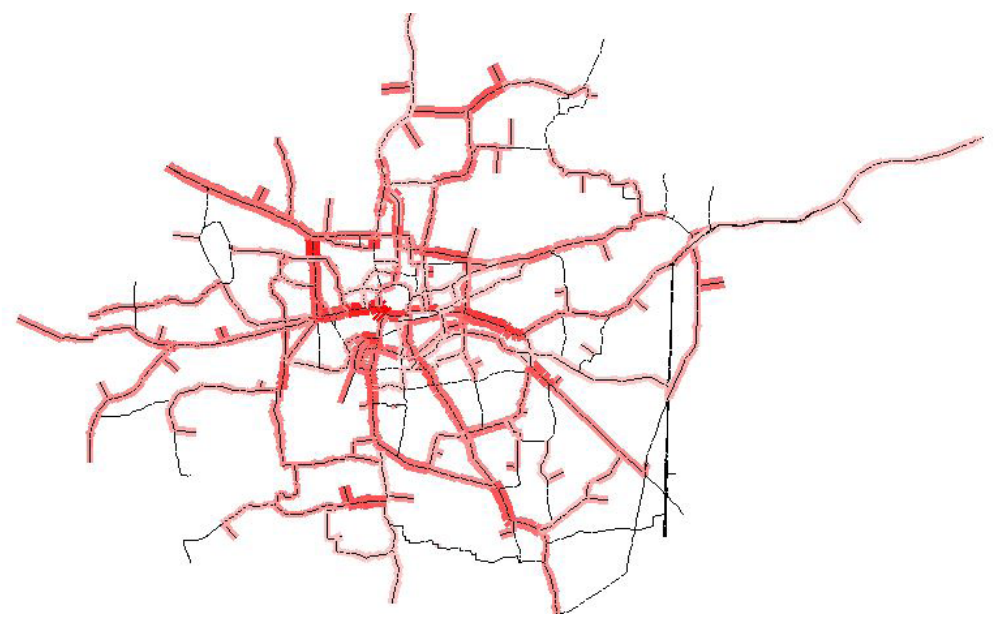

Fig. 5.

Traffic Flows on Each Link

Table 2

List of Congested Roads with V/C Ratio

\begin{tabular}{|c|l|c|}
\hline Sl. No. & \multicolumn{1}{|c|}{ Name Of Road } & V/C Ratio \\
\hline 1 & MG Road up to West fort junction & 1.02 \\
\hline 2 & KSRTC - Railway station road up to Divanjimoola & 1.38 \\
\hline 3 & West Fort to Poonkunnam junction & 1.18 \\
\hline 4 & College road near East fort junction & 1.43 \\
\hline 5 & Near Ashwini Hospital Junction & 0.76 \\
\hline 6 & Shoranur road near Patturaikkal & 1.73 \\
\hline
\end{tabular}

These roads connects some of the major roads entering the city such as Thrissur - Shoranur road, Thrissur- Kuttippuram road, ThrissurMannuthy road, Thrissur-Ernakulam road,
Thrissur-Vadanappally road and ThrissurKodungallur road. The congestion was mainly due to decreased width of roads and increased number of vehicles and trips. 


\subsection{Model Validation}

The developed travel demand model was validated by comparing the simulated volume and observed volume. The validation results are given in Table 3 . The error in volume on most of the roads was obtained below $20 \%$. The Relative Root Mean Square Error (RRMSE) obtained between the observed and simulated volumes of all the roads are $14 \%$. This shows that the developed model is able to capture the actual system.

Table 3

Comparison between Observed and Simulated Volumes

\begin{tabular}{|c|l|c|c|c|}
\hline $\begin{array}{c}\text { Sl. } \\
\text { No. }\end{array}$ & \multicolumn{1}{|c|}{ Name Of Road } & $\begin{array}{c}\text { Observed } \\
\text { (PCU) }\end{array}$ & $\begin{array}{c}\text { Simulated } \\
(\text { PCU) }\end{array}$ & Error \% \\
\hline 1 & MG Road & 117879 & 140436 & 19.14 \\
\hline 2 & Shoranur Road & 100928 & 109371 & 8.37 \\
\hline 3 & Palace Road up to Museum Jn. & 33698 & 38533 & 14.35 \\
\hline 4 & Palakkad Road & 144192 & 151929 & 5.37 \\
\hline 5 & High Road up to Kattukkaran Jn. & 94017 & 106403 & 13.17 \\
\hline 6 & MO Road up to Kannankulangara Jn. & 141918 & 159760 & 12.57 \\
\hline 7 & Kuruppam Road up to Baliya Jn. & 122345 & 142472 & 16.45 \\
\hline 8 & Poonkunnam to High Road (via) Divanjimoola, Chettiangadi, PO Jn. & 206240 & 215690 & 4.58 \\
\hline 9 & Divanjimoola to Kokkala to Kattukaran Jn. & 143933 & 144626 & 0.48 \\
\hline 10 & Puzhakkal to Poonkunnam to East Fort via,Aswini Hospital Jn. & 283117 & 329412 & 16.35 \\
\hline
\end{tabular}

\section{Application of the Travel Demand Model}

Various roads near CBD were found as congested in the trip assignment output. There arises an urgent need for reducing the congestion at these links for the sustained transportation system. The congestion can be reduced if the vehicle trips are rerouted without entering the CBD. Thus two ring roads $\mathrm{R} R 1$ and $\mathrm{R} R 2$ are proposed as a long term congestion mitigation measure to the city. The roads proposed are road joining Koorkkanchery-Chiyyaram road to Ayyanthole civil station road, TB road to Poothole road and Near Punkunnam (from SH69) to Peringavu junction. The new ring roads proposed in the highway network are highlighted as shown in Fig. 6.

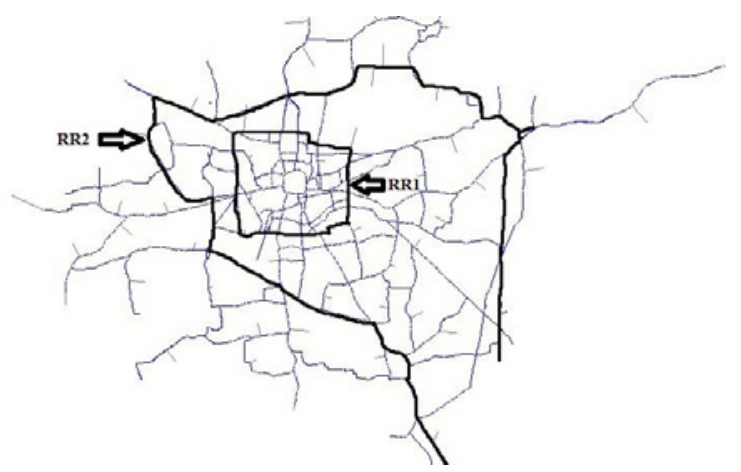

Fig. 6.

Proposed Outer Ring Roads 
The model was again run to obtain the new loaded network after including ring roads. Fig. 7 shows the new loaded network obtained after the introduction of ring roads. It can be seen from the figure that the volume has reduced at most of the roads near CBD. Table 4 shows the comparison between the observed volume and the newly simulated volume after introducing ring roads. It can be observed from the table that the volume has considerably reduced in all the congested roads. The reduction in volume ranges from $10 \%-20 \%$. The newly proposed roads diverted the volume from entering the Swaraj round which resulted in decrease in the congestion level at the city centre. The revised $\mathrm{V} / \mathrm{C}$ ratio obtained for these roads are shown in the Table 5.The $\mathrm{V} / \mathrm{C}$ ratio is found to be considerably reduced at all the roads after the introduction of ring roads. This is due to the rerouting of the vehicles from these roads to the proposed outerring roads.

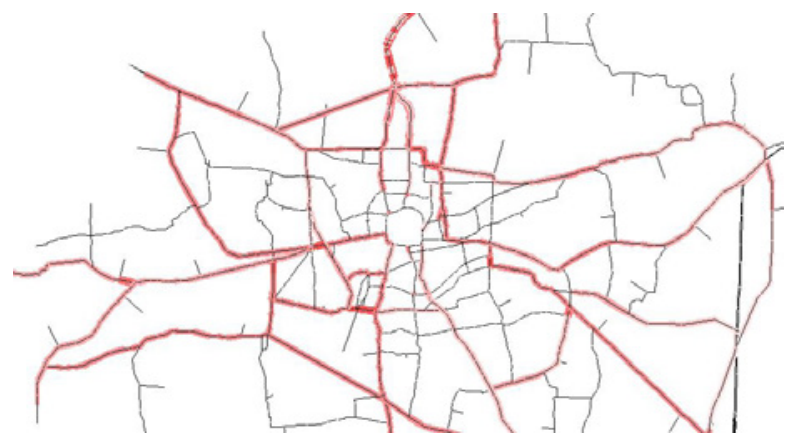

Fig. 7.

Loaded Network after Proposing Ring Roads

Table 4

Comparison of Volumes Before and After Introducing Ring Roads

\begin{tabular}{|c|l|c|c|c|}
\hline S1. No. & \multicolumn{1}{|c|}{ Name of the Road } & $\begin{array}{c}\text { Volume without } \\
\text { Ring Roads } \\
\text { (PCU) }\end{array}$ & $\begin{array}{c}\text { Volume with } \\
\text { Ring Roads } \\
\text { (PCU) }\end{array}$ & Error (\%) \\
\hline 1 & MG Road up to West fort junction & 101900 & 84777 & 20 \\
\hline 2 & KSRTC - Railway station road, Divanjimoola road & 83086 & 74510 & 10 \\
\hline 3 & Poonkunnam & 70825 & 45698 & 35 \\
\hline 4 & College road near Eastfort junction & 85810 & 64471 & 24 \\
\hline 5 & Near Ashwini Hospital junction & 54786 & 40342 & 26 \\
\hline 6 & Patturaikkal & 51993 & 44588 & 14 \\
\hline
\end{tabular}

Table 5

V/C Ratio Obtained after Introducing Ring Roads

\begin{tabular}{|c|l|c|}
\hline S1. No. & \multicolumn{1}{|c|}{ Name Of Road } & V/C Ratio \\
\hline 1 & MG Road up to West fort junction & 0.85 \\
\hline 2 & KSRTC - Railway station road up to Divanjimoola & 1.24 \\
\hline 3 & West Fort to Poonkunnam junction & 0.76 \\
\hline 4 & College road near East fort junction & 1.07 \\
\hline 5 & Near Ashwini Hospital Junction & 0.56 \\
\hline 6 & Shoranur road near Patturaikkal & 1.49 \\
\hline
\end{tabular}




\section{Conclusions}

Trip assignment model of a typical Indian city was developed in this study using four step travel demand model in Cube software. The model used all or nothing technique for trip assignment and it assigns all the trips between a particular origin and destination pair to that route which offers the minimum travel time. The model was accurate and the validation results showed that the difference between simulated volume and actual volume for most of the roads is below $20 \%$. Two proposed ring roads RR1 and RR2 lead to rerouting of the vehicles causing considerable reduction in congestion in the CBD by $10 \%$ $-35 \%$. Proposed outer ring roads will not be sufficient to manage traffic at the city centre efficiently. The land use of the area nearby the proposed ring roads is of residential type and the trip productions in the study area depend on number of commuters in the study area, vehicle ownership and age. The developed trip generation model showed that the trips between commercial/employment zones and residential zones were high. As the proposal can cause a decrease in travel time and reduced fuel consumption, there is a chance for increase in the utilization of these roads by the public in future. As the introduction of these roads can reduce the number of trips to city centre, there are possibilities for developing commercial centres near these locations. In addition to this, the model shows an increase in the $\mathrm{V} / \mathrm{C}$ ratio of approaching roads of junctions to which the proposed outer-ring roads are connected. Some solutions are required to reduce the possible congestion and increase in emissions at these junctions and road stretches. Possible solutions are given below:

- Development of Transit Hubs at major junctions of the ring roads and develop it as public transport routes with intermediate public transport or IPT as feeder modes;

- Provision of public transport chain services from these areas to city centres;

- Separate lanes for heavy vehicles along the ring roads or restrict the ring roads for heavy vehicles.

\section{References}

Hakimelahi, A.; Rao, K.K.; Dhingra, S.L.; Borzooei, S. 2016. Fuel Consumption Monitoring for Travel Demand Modeling, Transportation Research Procedia 17: 703-712.

Badoe, D.A.; Miller, E.J. 2000. Transportation-Land-Use Interaction: Empirical Findings in North America, and their Implications for Modeling, Transportation Research Part D: Transport and Environment 5(4): 235-263.

Berki, Z.; Monigl, J. 2017. Trip generation and distribution modelling in Budapest, Transportation Research Procedia 27:172-179.

Cascetta, E. 2001. Transportation Systems. In Transportation Systems Engineering: Theory and Methods. Springer, Boston, MA. 1-22.

Chakraborty, A.; Mishra, S. 2013. Land use and transit ridership connections: Implications for state-level planning agencies, Land Use Policy 30(1): 458-469.

D’Este, G. 1987. Trip assignment to radial major roads, Transportation Research Part B: Methodological 21(6): 433442.

Herawati, H. 2012. Trip Assignment Model With Consideration Of Vehicle Emission: Case For Cimahi City, Journal of the Civil Engineering Forum 20(1): 11891200.

Kalić, M.; Teodorović, D. 2003. Trip distribution Modelling Using Fuzzy Logic and A Genetic Algorithm, Transportation Planning and Technology 26(3): 213-238. 
Kumar, A.; Peeta, S. 2014. Slope-Based Path Shift Propensity Algorithm for the Static Traffic Assignment Problem, International Journal for Traffic and Transport Engineering 4(3): 297-319.

Abdel-Aal, M.M.M. 2014. Calibrating a Trip Distribution Gravity Model Stratified by the Trip Purposes for the City of Alexandria, Alexandria Engineering Journal 53(3): 677-689.

Nökel, K.; Wekeck, S. 2009. Boarding and Alighting in Frequency-Based Transit Assignment, Transportation Research Record 2111(1): 60-67.

de Dios Ortuzar, J.; Willumsen, L.G. 2011. Modelling transport. John Wiley \& Sons Ltd. UK. 607 p.

Paul, A. 2011. Axial Analysis: A Syntactic Approach to Movement Network Modeling, Institute of Town Planners, India Journal 8(1): 29-40.
Mehta, S.S.; Pansuria, D.M.; Savaliya, S.V.; Detroja, B.M.; Alwani, K.Y. 2017. Trip Distribution of Commercial Vehicle: A Case Study For Rajkot City, Journal of Transportation System 2(1):1-12.

Schmöcker, J.D.; Bell, M.G.; Kurauchi, F. 2008. A Quasi-Dynamic Capacity Constrained Frequency-Based Transit Assignment Model, Transportation Research Part B: Methodological 42(10): 925-945.

Teklu, F.; Watling, D.; Connors, R.D. 2007. A Markov Process Model for Capacity Constrained Transit Assignment. In Transportation and Traffic Theory 2007. Papers Selected for Presentation at ISTTT17Engineering Amsterdam, Boston: Elsevier.

Toilier, F.; Gardrat, M.; Routhier, J.L.; Bonnafous, A. 2018. Freight Transport Modelling in Urban Areas: the French Case of the FRETURB Model, Case Studies on Transport Policy 6(4): 753-764. 